\title{
Ein einfaches Verfahren zur Bestimmung des Halogens im Quecksilberchlorid sowie im Quecksilberbromid.
}

\author{
Von \\ MoRitz KoHN.
}

Erst jüngst habe ich in dieser Zeitschrift mitgeteilt, ${ }^{1}$ dafs das Quecksilberjodid sich durch Behandlung mit alkalischen Arsenitlösungen vollständig und durch Einwirkung von alkalischem Wasserstoffsuperoxyd zum grölsten Teil zerlegen lälst. In beiden Fällen scheidet sich Quecksilber in metallischer Form ab und das alkalische Filtrat enthält das gesamte Jod des verwendeten Quecksilberjodid̀s. Denn wie aus den damals mitgeteilten Zahlen zu entnehmen ist, läfst sich aus diesem Filtrat nach dem Ansäuern durch Zusatz von Silbernitrat das im Quecksilberjodid enthaltene Jod annähernd genau bestimmen. Diese Beobachtungen haben mich voraussehen lassen, dafs die Zersetzung des Quecksilberchlorids und des Quecksilberbromids unter dem Einfluls von Alkali in Gegenwart von Wasserstoffsuperoxyd sich noch leichter und vollständiger vollziehen und demnach eine genaue Bestimmung des Halogens in diesen Verbindungen ermöglichen werde. Man verfährt zu diesem Zwecke ebenso wie in meiner früheren Abhandlung beim Jodid auseinandergesetzt wurde. Nur genügen hier schon geringere Alkalimengen, auf $0.5-0.6 \mathrm{~g}$ Substanz etwa $2 \mathrm{~g}$ reinsten, aus metallischem Natrium bereiteten völlig halogenfreien Natriumbydroxyds. Die Umsetzung beginnt schon in der Kälte und wird durch allmähliches gelindes Erwärmen vervollständigt. Um das überschüssige Wasserstoffsuperoxyd zu zerstören, muls man schliefslich doch bis nahe auf Siedetemperatur erhitzen. Das abgeschiedene Quecksilber lärst sich verhältnismälsig leicht durch Filtration entfernen; es wird auf dem Filter mit Wasser gründlich ausgewaschen. Das alkalische Filtrat, welches bei Anwendung von Quecksilberjodid stets merkliche Mengen Quecksilber enthält, ist hier völlig frei von Quecksilber. Es wird mit verdünnter Salpetersäure angesäuert

${ }^{1}$ M. Koнn, Zwei Beobachtungen über die Zerlegung des Quecksilberjodids. 
und mit Silbernitrat in märsigem Überschufs gefällt. Das Halogensilber wird im Goochtiegel filtriert und nach dem Trocknen bei $130^{\circ}$ gewogen. Bei der Bestimmung des Chlorgehaltes in reinstem Quecksilberchlorid nach dieser Methode wurde gefunden:

I. $0.5088 \mathrm{~g} \mathrm{HgCl}_{2}$ lieferten $0.5373 \mathrm{~g} \mathrm{AgCl}$.

II. $0.5820 \mathrm{~g} \mathrm{HgCl}_{2}$ lieferten $0.6215 \mathrm{~g} \mathrm{AgCl}$.

III. $0.5264 \mathrm{~g} \mathrm{HgCl}_{2}$ lieferten $0.5570 \mathrm{~g} \mathrm{AgCl}$.

In 100 Teilen:

\begin{tabular}{ccccc} 
& \multicolumn{3}{c}{ Gefunden: } & Berechnet für \\
& I. & II. & III. & $\mathrm{HgCl}_{2}:$ \\
$\mathrm{Cl} . \quad$ & 26.11 & 26.40 & 26.16 & 26.17
\end{tabular}

Bei der Bestimmung des Bromgehaltes im Quecksilberbromid nach dieser Methode wurde gefunden:

I. $0.5511 \mathrm{~g} \mathrm{HgBr}_{2}$ lieferten $0.5741 \mathrm{~g} \mathrm{AgBr}$.

II. $0.5568 \mathrm{~g} \mathrm{HgBr}_{2}$ lieferten $0.5837 \mathrm{~g} \mathrm{AgBr}$.

III. $0.5121 \mathrm{~g} \mathrm{HgBr}_{2}$ lieferten $0.5380 \mathrm{~g} \mathrm{AgBr}$.

In 100 Teilen:

$\begin{array}{cccc} & \text { Gefunden: } & \text { Berechnet für } \\ \text { I. } & \text { II. } & \text { III. } & \mathrm{HgBr}_{2}: \\ 44.33 & 44.61 & 44.71 & 44.43\end{array}$

Das Quecksilberchlorür wird bekanntlich durch Alkali allein vollständig ${ }^{1}$ zersetzt. Zur Bestimmung des Halogens im Quecksilberchlorid sowie im Quecksilberbromid wurde bisher empfohlen, das Quecksilber entweder durch Behandlung mit metallischem Zink oder Cadmium zu entfernen oder aber mit Schwefelwasserstoff bei etwa $50^{\circ}$ in Form des Sulfids auszufällen. In diesem Falle mufs dann aus dem Filtrat der absorbierte Schwefelwasserstoff durch Einleiten von Kohlendioxyd vollständig entfernt werden, worauf erst mit Silbernitrat gefällt werden kann.

Es ist wohl ohne weiteres einleuchtend, dafs mein Verfahren nicht nur viel einfacher in der Ausführung ist, sondern auch weitaus rascher zum Ziele führt; dergleichen ist ein Verlust an Halgen im Laufe der Operation ausgeschlossen.

${ }^{1} Z$. anorg. Chem. 13, 408 u. f.

Wien, II. chem. Universitätslaboratorium, 15. Mai 1908.

Bei der Redaktion eingegangen am 26. Mai 1908. 